\title{
Depression in type 1 diabetes was associated with high levels of circulating galectin-3
}

\author{
Eva Olga Melin ${ }^{1,2,3}$, Jonatan Dereke ${ }^{4}$, Maria Thunander ${ }^{1,2,5}$ and Magnus Hillman ${ }^{4}$ \\ 'Department of Clinical Sciences, Endocrinology and Diabetes, Lund University, Faculty of Medicine, Lund, Sweden \\ ${ }^{2}$ Department of Research and Development, Region Kronoberg, Växjö, Sweden \\ ${ }^{3}$ Region Kronoberg, Primary Care, Växjö, Sweden \\ ${ }^{4}$ Department of Clinical Sciences Lund, Lund University, Faculty of Medicine, Diabetes Research Laboratory, Lund, Sweden \\ ${ }^{5}$ Department of Internal Medicine, Endocrinology and Diabetes, Central Hospital, Växjö, Sweden \\ Correspondence should be addressed to E O Melin: eva.melin@kronoberg.se
}

\section{Abstract}

Objective: Neuroinflammatory responses are implicated in depression. The aim was to explore whether depression in patients with type 1 diabetes (T1D) was associated with high circulating galectin-3, controlling for metabolic variables, s-creatinine, life style factors, medication and cardiovascular complications.

Design: Cross-sectional.

Methods: Participants were T1D patients ( $n=283,56 \%$ men, age 18-59 years, diabetes duration $\geq 1$ year). Depression was assessed by Hospital Anxiety and Depression Scaledepression subscale. Blood samples, anthropometrics and blood pressure were collected,

\section{Key Words}

- biomarker

- depression

- cardiovascular complications

- galectin-3

- neuroinflammation

- type 1 diabetes and supplemented with data from medical records and the Swedish National Diabetes Registry. Galectin-3 $\geq 2.562 \mu \mathrm{g} / \mathrm{l}$, corresponding to the 85 th percentile, was defined as high galectin-3.

Results: Median (quartile ${ }_{1}$, quartile ${ }_{3}$ ) galectin-3 $(\mu \mathrm{g} / \mathrm{l})$ was $1.3(0.8,2.9)$ for the 30 depressed patients, and $0.9(0.5,1.6)$ for the 253 non-depressed, $P=0.009$. Depression was associated with high galectin-3 in all the 283 patients (adjusted odds ratio (AOR) 3.5), in the 161 men (AOR 3.4), and in the 122 women (AOR 3.9). HbA1c, s-lipids, s-creatinine, blood pressure, obesity, smoking, physical inactivity, cardiovascular complications and drugs (antihypertensive, lipid lowering, oral antidiabetic drugs and antidepressants) were not associated with high galectin-3.

Conclusions: This is the first study to show an association between depression and galectin-3. Depression was the only explored parameter associated with high circulating galectin-3 levels in 283 T1D patients. High galectin-3 levels might contribute to the increased risk for Alzheimer's disease, cardiovascular and all-cause mortality observed in persons with depression. Potentially, in the future, treatment targeting galactin-3 might improve the prognosis for patients with high galectin-3 levels.

Endocrine Connections (2018) 7, 819-828

\section{Introduction}

Depression is associated with type 1 diabetes (T1D), Alzheimer's disease, increased coronary heart disease and both coronary and all-cause mortality $(1,2,3)$. T1D has a serious impact on mental health, indicated by the more than doubled relative risk rate for suicide in persons with
T1D (4). Several biological links between depression and somatic disorders have been demonstrated including metabolic changes, dysregulation of the hypothalamicpituitary-adrenal axis and activation of the innate immune system causing systemic inflammation $(2,3,5,6,7)$. http://www.endocrineconnections.org https://doi.org/10.1530/EC-18-0108
() 2018 The authors Published by Bioscientifica Ltd

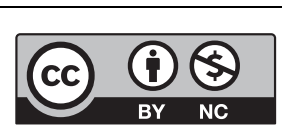

This work is licensed under a Creative Commons Attribution-NonCommercial 4.0 International License. 
We have previously shown in these patients with T1D that depression was associated with inadequate glycaemic control (8), and with high midnight salivary cortisol secretion $(9,10)$, but not with obesity $(11)$.

Galectin-3 is a soluble $\beta$-galactoside binding lectin, which is expressed in several cells such as activated macrophages, microglia, mast cells and in tissues such as subsets of neurons in the brain, the heart, the epithelium of the gastrointestinal and respiratory tracts, and the kidney $(12,13,14)$. Galectin-3 is implicated in a variety of biological processes including immune activation, fibrosis, angiogenesis and neurodegeneration $(12,14,15$, $16,17,18)$.

Higher circulating galectin-3 concentrations have been associated with heart failure independent of aetiology, and with increased cardiovascular and allcause mortality in the general population $(14,19,20,21)$. Galectin-3 has pleiotropic effects in CNS inflammation, combining pro-inflammatory roles with remodelling capacity in damaged CNS tissues (16). Experimental studies have shown that galectin-3 contributes to microglial activation and prolonged inflammatory responses in the brain (17). In Alzheimer's disease, increased levels of serum galectin-3 have been demonstrated (15). Significant associations have previously been found between galectin-3 and age, sex, type 2 diabetes mellitus, hypertension, hypercholesterolemia, triglycerides, LDL, BMI, renal dysfunction and smoking $(19,21,22,23)$. Metformin in type 2 diabetes mellitus has, however, been linked to lower galectin-3 levels (22). Even though the main focus of galectin-3 has been on its function as a proinflammatory mediator, there are also studies showing galectin-3 acting as a decoy to advanced glycation endproducts which could indicate some kind of protective function in patients with diabetes (24).

Our hypothesis was that depression is associated with high galectin-3 levels in patients with T1D as neuroinflammatory processes are implicated in depression $(2,3,5,7)$, and since both galectin-3 and depression have been linked to Alzheimer's disease, as well as to increased cardiovascular and all-cause mortality $(1,2,14,17,19,20$, $21)$. To our knowledge, galectin-3 has not previously been explored in depressed patients or in patients with T1D. The aim was to explore whether depression in patients with T1D was associated with galectin-3, and control for metabolic variables, s-creatinine, medication and cardiovascular complications. This knowledge could add to our current understanding of depression in T1D and prepare for better diagnostic or treatment strategies in the future.

$$
\text { http://www.endocrineconnections.org }
$$

\section{Subjects and methods}

This study has a cross-sectional design and is one of five baseline analyses $(8,9,10,11)$ for a randomized controlled trial (ClinicalTrials.gov: NCT01714986) where 'Affect School with Script Analysis' was tried against 'Basic Body Awareness Therapy' for persons with diabetes, inadequate glycaemic control and psychological symptoms $(25,26)$. The patients who attend the clinic every 6 months for regular follow-up visits were consecutively recruited by specialist diabetes physicians or diabetes nurses during a 9-month period, 25 March 2009 to 28 December 2009, from one hospital diabetes outpatient clinic. The catchment population was 125,000 in southern Sweden. Inclusion criteria were T1D with $\geq 1$-year duration, in patients of 18-59 years of age. Exclusion criteria were cancer, hepatic failure, end-stage renal disease, psychotic disorder, bipolar disorder, severe personality disorder, severe substance abuse, cognitive deficiency (due to stroke, dementia or mental retardation) or inadequate knowledge of Swedish. In this study, 283 persons with T1D were included, $65 \%$ of the eligible patients (Fig. 1). A questionnaire was used to assess self-reported depression. Blood and saliva samples, anthropometrics and blood pressure were collected and supplemented with data from medical records and the Swedish National Diabetes Registry (S-NDR) $(27,28)$. In case of missing values, galectin-3 levels were compared between patients with and without the missing values. The study complies with the declaration of Helsinki and was approved by the Regional Ethical Review Board of Linköping University, Linköping, Sweden (Registration no. M120-07, T89-08). All participants provided written informed consent.

\section{Self-reported depression}

Self-reported depression was assessed by the Hospital Anxiety and Depression Scale-Depression subscale (HADS-D) which consists of 7 statements, with 4 response alternatives from 0 to 3 . The cut-off level $\geq 8$ points was used as recommended by the constructors of the test (29). HADS-D is a useful instrument for detecting symptoms of depression, both at an individual and a collective level, and has been demonstrated to have a good reliability and discriminant validity (30). Imputation of a missing value was performed in one case.

\section{Blood samples}

Galectin-3 was analysed using a commercial human DuoSet ELISA and supplementary ancillary kit

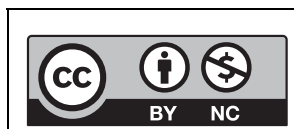
This work is licensed under a Creative Commons
Attribution-NonCommercial 4.0 International License. 
Type 1 diabetes mellitus

Age $18-59$ years. Diabetes duration $\geq 1$ year
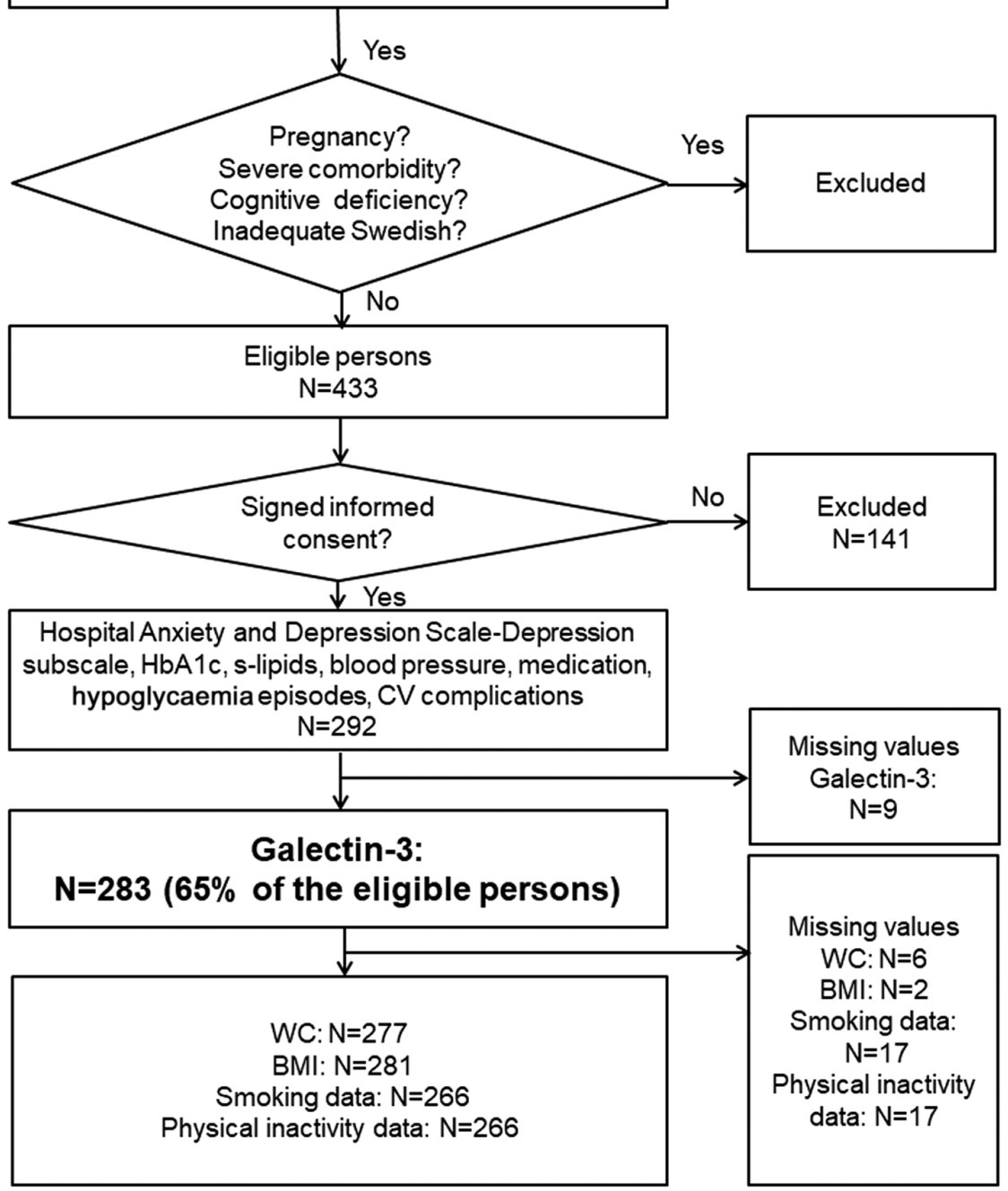

Figure 1

Flowchart describing the 283 included participants, included variables and numbers of missing values.

(R\&D Systems). Patient plasma samples were diluted 1:2 in PBS supplemented with 1\% BSA and run in duplicates. The ELISA analysis was performed according to the manufacturer's instructions. Absorbance was measured at $450-580 \mathrm{~nm}$ in a FLUOstar optima plate reader (BMG Labtech Gmbh, Ortenberg, Germany). Concentrations of unknown samples were calculated using a four-parameter logistic regression curve. The intra-assay coefficient of variation for the analysis was $4.3 \%$.

Galectin-3 was available for 283 patients (65\% of the eligible patients) (Fig. 1). Galectin-3 ( $\mu \mathrm{g} / \mathrm{l})$ was dichotomized, and cut-off levels were determined for the 75 th, the 80 th, the 85 th and the 90th percentiles. Galectin-3 $\geq 2.562 \mu \mathrm{g} / \mathrm{l}$, corresponding to the 85th percentile, was defined as high galectin-3, and was used in the further statistical analyses.

http://www.endocrineconnections.org https://doi.org/10.1530/EC-18-0108

(c) 2018 The authors Published by Bioscientifica Ltd
The 283 patients with galectin-3 measurements were compared to the 9 patients without galectin-3 measurements. There were no differences for the prevalence of self-reported depression, abdominal obesity, general obesity, physical inactivity, smoking, cardiovascular complications, antidepressants, oral antidiabetic drugs (OADs) in addition to insulin, lipid lowering drugs (LLDs) or antihypertensive drugs (AHD); or for the medians of HbA1c, s-lipids, creatinine, systolic or diastolic blood pressure, age or diabetes duration (all $P$ values $\geq 0.09$ )

Venous HbA1c (mmol/mol (\%)) was analysed with HPLC - variant II, Turbo analyser (Bio-Rad). High HbA1c levels were defined as $\mathrm{HbA} 1 \mathrm{c}>70 \mathrm{mmol} / \mathrm{mol}$ (>8.6\%) (8).

Total cholesterol (TC), triglycerides, LDL and HDL $(\mathrm{mmol} / \mathrm{l})$ were collected after an overnight fast, and

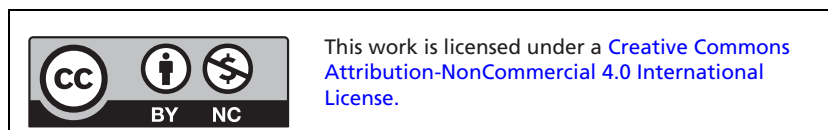


measured directly (31), using the enzymatic colour test (Olympus AUß, Tokyo, Japan).

Creatinine $(\mu \mathrm{mol} / \mathrm{l})$ was assayed by an AU2700® instrument (Beckman Coulter, Brea, CA, USA).

\section{Anthropometrics and blood pressure}

Waist circumference (WC), weight, length and blood pressure were measured according to standard procedures by a nurse. Abdominal obesity was defined as WC $\geq 1.02 \mathrm{~m}$ for men and as WC $\geq 0.88 \mathrm{~m}$ for women. General obesity was defined as BMI $\geq 30 \mathrm{~kg} / \mathrm{m}^{2}$ for both genders (32). Galectin-3 levels did not differ between the 6 patients without and the 277 patients with WC measurements $(P=0.67)$, and did not differ between the two patients without and the 281 patients with BMI values $(P=0.11)$.

\section{Episodes of hypoglycaemia}

A severe episode of hypoglycaemia was defined as needing help from another person. Episodes during the last 6 months prior to recruitment were registered.

\section{Smoking and physical inactivity}

Smokers were defined as having smoked any amount of tobacco during the last year.

Physical inactivity was defined as moderate activities, such as 30 min of walking, less than once a week. There were 17 missing values both for smoking and for physical inactivity. Galectin-3 levels did not differ between the 17 without data and the 266 with data, neither for smoking $(P=0.72)$ nor for physical inactivity $(P=0.87)$.

\section{Cardiovascular complications}

Cardiovascular complications were defined as ischaemic heart disease, cardiac failure, stroke or transient ischemic attack.

\section{Medication}

Antidepressants were selective serotonin reuptake inhibitors (SSRIs), selective norepinephrine reuptake inhibitors (SNRIs) and/or specific serotonergic antidepressants (N06AB, N06AX16, N06AX11).

Diabetes specific treatment was divided into two groups: Insulin only (multiple daily insulin injections or continuous subcutaneous insulin infusion), or insulin combined with OAD (ATC code A10BA02). The indications

$$
\text { http://www.endocrineconnections.org }
$$

for OAD prescription in addition to insulin were obesity or insulin resistance.

LLD were HMG CoA reductase inhibitors (statins) (C10AA). Indications for LLD were TC $>4.5 \mathrm{mmol} / 1$ $(>1.74 \mathrm{mg} / \mathrm{dl})$ and/or LDL $>2.5 \mathrm{mmol} / \mathrm{l} \quad(>97 \mathrm{mg} / \mathrm{dl})$ according to the Swedish national guidelines in 2009 (33).

AHD were calcium antagonists (ATC codes C08CA0102); ACE inhibitors (ATC codes C09AA-BA); angiotensin II antagonists (ATC codes C09CA-DA); diuretics (ATC code C03A); and/or selective beta-adrenoreceptor antagonists (ATC code $\mathrm{C} 07 \mathrm{AB}$ ). Indications for AHD were systolic blood pressure $>130 \mathrm{mmHg}$ and/or diastolic blood pressure $>80 \mathrm{mmHg}$ according to the Swedish national guidelines in 2009 (33).

\section{Statistical analysis}

Analysis of data distribution using histograms revealed that age, diabetes duration, galectin-3 and triglycerides were not normally distributed. Data were presented as median values (quartile $\left(\mathrm{q}_{1}, \mathrm{q}_{3}\right)$ ), and analyses were performed with Mann-Whitney $U$ test. Fisher's exact tTest (two-tailed) was used to analyse categorical data. In order to establish a cut-off level for galectin-3, the 75th, 80th, 85th and 90th percentiles of galectin-3 were entered into a backward elimination multiple logistic regression analysis with self-reported depression as the dependent variable. Crude odds ratios (CORs) for the associations with galectin-3 $\geq 2.562 \mu \mathrm{g} / 1$ (corresponding to the 85 th percentile) were calculated. Variables with $P \leq 0.10$, and gender and age independent of $P$ value, were entered into multiple logistic regression analyses (Backward: Wald). The Hosmer and Lemeshow test for goodness-offit and Nagelkerke $R^{2}$ were used to evaluate each multiple logistic regression analysis model. CIs of 95\% were used. Imputation for a missing value in the HADS-D scale was performed using multinomial regression on the other variables in the scale in one case. $P<0.05$ was considered statistically significant. SPSS version 18 (IBM) was used.

\section{Results}

Median $\left(\mathrm{q}_{1}, \mathrm{q}_{3}\right)$ galectin-3 $(\mu \mathrm{g} / \mathrm{l})$ levels were for all $(n=283)$ $0.9(0.6,1.7)$; for the men $(n=161) 1.0(0.6,2.0)$, and for the women $(n=122) 0.9(0.5,1.4), P=0.15$ for gender difference.

In Table 1, comparisons are performed between the 30 depressed and the 253 non-depressed patients. Median galectin-3 levels were significantly higher for

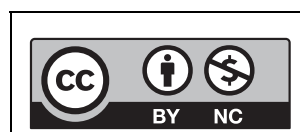

This work is licensed under a Creative Commons Attribution-NonCommercial 4.0 International License. 
Table 1 Comparisons between 30 depressed and 253 non-depressed patients with T1D.

\begin{tabular}{|c|c|c|c|}
\hline & Depression & No depression & $P$ value $^{a}$ \\
\hline$n$ & $30(11)$ & $253(89)$ & \\
\hline \multicolumn{4}{|l|}{ Gender } \\
\hline Men & $16(10)$ & $145(90)$ & 0.70 \\
\hline Women & $14(12)$ & $108(88)$ & \\
\hline \multicolumn{4}{|l|}{ Galectin-3 } \\
\hline All & $1.3(0.8,2.9)$ & $0.9(0.5,1.6)$ & $0.009^{b}$ \\
\hline Men & $1.8(0.9,3.7)$ & $0.9(0.6,1.9)$ & $0.021^{b}$ \\
\hline Women & $1.0(0.8,2.7)$ & $0.9(0.5,1.4)$ & $0.18^{b}$ \\
\hline $\begin{array}{l}\text { Cardiovascular } \\
\text { complications }\end{array}$ & $4(40)$ & $6(60)$ & 0.014 \\
\hline Antidepressants & $10(44)$ & $13(56)$ & $<0.001$ \\
\hline
\end{tabular}

Data are presented as $n(\%)$ or median $\left(q_{1}, q_{3}\right)$.

${ }^{a}$ Fisher's exact test unless otherwise indicated; ${ }^{b}$ Mann-Whitney $U$ test.

the depressed patients compared to the non-depressed, $P=0.009$. The prevalence of cardiovascular complications was higher in the depressed patients than in the nondepressed, $P=0.014$.

In Table 2 , the prevalence of depression is presented for four different galectin-3 cut-off levels, corresponding to the 75 th, the 80 th, the 85 th and the 90th percentiles of galectin-3. The $P$ values were significant for the 85 th percentile $(P=0.006)$, and for the 80th percentile $(P=0.026)$. The association between depression and the 85 th percentile of galectin-3 was significant (AOR 3.5 (CI 1.5-8.0), $P=0.004$ ), but not between depression and the following percentiles of galectin-3: the 75th (AOR 0.8 (CI $0.2-3.5), P=0.73$ ), the 80th (AOR 1.2 (CI 0.1-20.3), $P=0.92$ ) or the 90th percentile (AOR 0.7 (CI 0.2-2.3), $P=0.61$ ).

In Table 3, baseline characteristics for all the 283 T1D patients, and comparisons between the 42 patients with galectin-3 levels $\geq 2.562 \mu \mathrm{g} / 1$ and the 241 patients with galectin-3 levels $<2.562 \mu \mathrm{g} / \mathrm{l}$ are presented. Patients with galectin-3 $\geq 2.562 \mu \mathrm{g} / \mathrm{l}$ had a higher prevalence of cardiovascular complications $(P=0.045)$.

In Table 4, associations with high galectin-3 $(\geq 2.562 \mu \mathrm{g} / \mathrm{l})$ are presented. Depression was associated with high galectin-3 in all the 283 patients (AOR 3.5), in the 161 men (AOR 3.4), and in the 122 women (AOR 3.9). Cardiovascular complications were only associated with high galectin-3 in simple logistic regression (COR 4.1), but not when age, depression and gender were included in the analysis.

In all the 283 patients, the association between cardiovascular complications and depression was significant: COR (CI), 6.6 (1.7-24.8), $P=0.005$; and between cardiovascular complications and age: COR (CI), 1.18 (1.06-1.31), $P=0.003$; but not between cardiovascular complications and gender, $P=0.77$.

\section{Discussion}

The main findings were that self-reported depression was associated with high galectin-3 $(\geq 2.562 \mu \mathrm{g} / \mathrm{l})$ for all, and for each gender analysed separately. There were no associations between high galectin-3 and the following explored variables: HbA1c, s-lipids, blood pressure, obesity, s-creatinine, drugs (antidepressants, OADs, LLDs or AHDs) or cardiovascular complications. There was a strong association between depression and cardiovascular complications.

The association between depression and high galectin-3 in patients with T1D is a new finding. To our knowledge, galectin-3 has neither been explored in patients with T1D previously, nor has the association between galectin-3 and depression been explored. The results supported our hypothesis that the depressed patients with T1D had higher galectin-3 levels than the non-depressed patients. Associations between high galectin-3 and potential diabetes-related confounders such as HbA1c, obesity, s-lipids, blood pressure, severe hypoglycemia, s-creatinine, smoking, physical inactivity, cardiovascular complications and drugs (antihypertensive, lipid lowering, oral antidiabetic and antidepressants) were systematically explored. Gender subanalyses were performed. Inclusion and exclusion criteria were

Table 2 The prevalence of depression calculated for four galectin-3 cut-off levels, corresponding to the 75th, 80th, 85th and 90th percentiles.

\begin{tabular}{|c|c|c|c|c|c|c|c|c|c|c|c|c|c|}
\hline & \multicolumn{13}{|c|}{ Galectin-3 ( $\mu \mathrm{g} / \mathrm{L})$} \\
\hline & \multirow{2}{*}{$\frac{\text { Range }}{\underline{0.001-100.0}}$} & \multicolumn{3}{|c|}{ 75th percentile } & \multicolumn{3}{|c|}{ 80th percentile } & \multicolumn{3}{|c|}{ 85th percentile } & \multicolumn{3}{|c|}{ 90th percentile } \\
\hline & & $<1.681$ & $\geq 1.681$ & $P$ value & $<2.102$ & $\geq 2.102$ & $P$ value & $<2.562$ & $\geq 2.562$ & $P$ value & $<3.272$ & $\geq 3.272$ & $P$ value \\
\hline \multicolumn{14}{|c|}{$\overline{\text { Depression }}$} \\
\hline All & $30(11)$ & $18(60)$ & $12(40)$ & 0.074 & $19(63)$ & $11(37)$ & 0.026 & $20(67)$ & $10(33)$ & 0.006 & $24(80)$ & $6(20)$ & 0.096 \\
\hline Men & $16(10)$ & $8(50)$ & $8(50)$ & 0.095 & $9(56)$ & $7(44)$ & 0.068 & $10(62)$ & $6(38)$ & 0.037 & $11(69)$ & $5(31)$ & 0.031 \\
\hline Women & $14(12)$ & $10(71)$ & $4(29)$ & 0.28 & $10(71)$ & $4(29)$ & 0.11 & $10(71)$ & $4(29)$ & 0.056 & $13(93)$ & $1(7)$ & $>0.99$ \\
\hline
\end{tabular}

Data are presented as $n(\%)$. Fisher's exact test.

$$
\begin{array}{lr}
\text { http://www.endocrineconnections.org } & \text { ○ } 2018 \text { The authors } \\
\text { https://doi.org/10.1530/EC-18-0108 } & \text { Published by Bioscientifica Ltd }
\end{array}
$$


Table 3 Baseline characteristics for all 283 T1D patients, and comparisons between patients with galectin-3 levels below and above the 85th percentile.

\begin{tabular}{|c|c|c|c|c|}
\hline & \multicolumn{4}{|c|}{ Galectin-3 ( $\mu \mathrm{g} / \mathrm{L})$} \\
\hline & $0.001-100.0$ & $<2.562$ & $\geq 2.562$ & $P$ value $^{\text {a }}$ \\
\hline$n$ & 283 & 241 & 42 & \\
\hline \multicolumn{5}{|l|}{ Gender } \\
\hline Men & $161(57)$ & $133(83)$ & $28(17)$ & 0.18 \\
\hline Women & $122(43)$ & $108(88)$ & $14(12)$ & \\
\hline Age (years) & $(18-59)$ & $42(31,50)$ & $46(36,54)$ & $0.050^{\mathrm{b}}$ \\
\hline Diabetes duration (years) & $(1-55)$ & $19(10,30)$ & $24(16,31)$ & $0.095^{\mathrm{b}}$ \\
\hline \multicolumn{5}{|l|}{$\mathrm{HbA1c}$} \\
\hline$(\mathrm{mmol} / \mathrm{mol})$ & $(25-110)$ & $64(54,72)$ & $61(54,67)$ & $0.40^{\mathrm{b}}$ \\
\hline$(\%)$ & $(4.4-12.2)$ & $8.0(7.1,8.7)$ & $7.7(7.1,8.3)$ & \\
\hline $\mathrm{TC}^{\mathrm{c}}(\mathrm{mmol} / \mathrm{L})$ & $(2.1-10.9)$ & $4.6(4.1,5.2)$ & $4.6(4.1,5.0)$ & $0.73^{\mathrm{b}}$ \\
\hline Triglycerides (mmol/L) & $(0.1-5.9)$ & $0.9(0.7,1.3)$ & $1.0(0.7,1.2)$ & $0.42^{\mathrm{b}}$ \\
\hline $\mathrm{LDL}^{\mathrm{d}}(\mathrm{mmol} / \mathrm{L})$ & $(0.6-8.3)$ & $2.8(2.4,3.3)$ & $2.8(2.3,3.3)$ & $0.56^{\mathrm{b}}$ \\
\hline $\mathrm{HDL}^{\mathrm{e}}(\mathrm{mmol} / \mathrm{L})$ & $(0.3-2.7)$ & $1.5(1.3,1.8)$ & $1.6(1.3,1.9)$ & $0.55^{\mathrm{b}}$ \\
\hline Creatinine $(\mu \mathrm{mol} / \mathrm{L})$ & $(28-182)$ & $70(61,78)$ & $70(64,80)$ & $0.64^{\mathrm{b}}$ \\
\hline Abdominal obesity & $46(16)$ & $40(87)$ & $6(13)$ & $>0.99$ \\
\hline General obesity & $34(12)$ & $31(91)$ & $3(9)$ & 0.44 \\
\hline Systolic BP (mmHg) & $(90-160)$ & $120(110,130)$ & $120(114.131)$ & $0.74^{\mathrm{b}}$ \\
\hline Diastolic BP (mmHg) & $(55-100)$ & $70(70,75)$ & $70(65,80)$ & $0.58^{\mathrm{b}}$ \\
\hline Hypoglycaemia (severe episodes) & $12(4)$ & $9(75)$ & $3(25)$ & 0.40 \\
\hline Smoking & $28(10)$ & $23(82)$ & $5(18)$ & 0.59 \\
\hline Physical inactivity & $31(12)$ & $27(87)$ & $4(13)$ & $>0.99$ \\
\hline Cardiovascular complications & $10(3)$ & $6(60)$ & $4(40)$ & 0.045 \\
\hline Antidepressants & $23(8)$ & $19(83)$ & $4(17)$ & 0.76 \\
\hline $\mathrm{OAD}^{f}$ and insulin & $15(5)$ & $14(93)$ & $1(7)$ & 0.71 \\
\hline LLD $^{g}$ & $131(46)$ & $111(85)$ & $20(15)$ & 0.87 \\
\hline$A H D^{h}$ & $95(34)$ & $79(83)$ & $16(17)$ & 0.60 \\
\hline
\end{tabular}

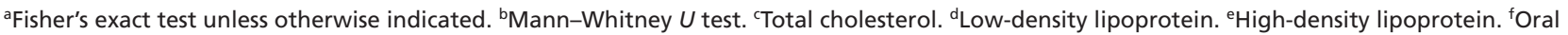
antidiabetic drugs. ' Lipid lowering drugs. ${ }^{\text {h}}$ Antihypertensive drugs. BP, blood pressure.

well defined. Patients with cognitive deficiencies were excluded, so no patients diagnosed with dementia were included.

One weakness was the limited number of patients within several subgroups. There were only 10 persons with cardiovascular complications, and the association between cardiovascular complications and high galectin-3 was not significant when adjusted for depression and age. The $P$ value was 0.10 for the association between high galectin-3 and cardiovascular complications in the six men, indicating that this might be a type 2 error. In a larger setting, significant associations between cardiovascular complications and high galectin-3 levels could be expected $(14,19,20,21)$. Only 14 women and 16 men had self-reported depression. Despite the low number of depressed patients, the associations between depression and high galectin-3 were significant for all, and for the men and women analysed separately. The diagnosis of depression was not confirmed by a structured interview. HADS-D has, however, shown high validity for assessing depressive symptoms both at an individual and a collective level (30). We have also previously found strong

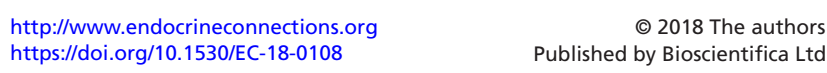

associations between self-reported depression assessed by HADS-D and clinical psychiatric diagnoses, and between self-reported depression and antidepressant use in these patients (8). Another weakness is that we did not have a control group without T1D, but this was not necessary for exploring our hypothesis that galectin-3 is higher in depressed than in non-depressed patients with T1D. One difficulty we had to address in this research was that there is no established consensus regarding detrimental galectin-3 levels. Therefore, we explored the associations between depression and four different galectin-3 cut-off levels. In the further analyses, we chose the galectin-3 level that corresponded to the 85th percentile of galectin-3, as this was the level that showed the highest association with depression. Depression is associated with increased risk for cardiovascular and all-cause mortality, and with increased risk for Alzheimer's disease $(1,2)$. According to previous research, higher circulating galectin-3 concentrations are associated with heart failure independent of aetiology, and with increased cardiovascular and all-cause mortality in the general population $(14,19,20,21)$. Increased levels of serum galectin-3 have also been demonstrated in

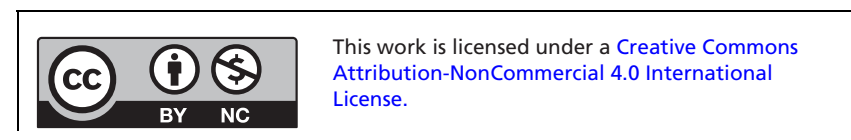


Table 4 Associations with high galectin-3 presented for all 283 T1D patients and for each gender separately.

\begin{tabular}{|c|c|c|c|c|c|c|c|c|}
\hline & \multicolumn{8}{|c|}{ High galectin-3 $(\geq 2.562 \mu \mathrm{g} / \mathrm{L})$} \\
\hline & \multicolumn{4}{|c|}{ All } & \multicolumn{2}{|l|}{ Men } & \multicolumn{2}{|l|}{ Women } \\
\hline & $\operatorname{COR}(95 \% \mathrm{Cl})$ & $P$ value & AOR $(95 \% \mathrm{Cl})$ & $P$ value ${ }^{a}$ & AOR $(95 \% \mathrm{Cl})$ & $P$ value ${ }^{b}$ & AOR $(95 \% \mathrm{Cl})$ & $P$ value ${ }^{c}$ \\
\hline Gender (men) & $1.6(0.8-3.2)$ & 0.17 & $1.6(0.8-3.3)$ & 0.19 & - & - & - & - \\
\hline Age (per year) & $1.03(1.00-1.06)$ & 0.053 & $1.03(1.00-1.06)$ & 0.095 & $1.02(0.98-1.06)$ & 0.42 & $1.03(0.97-1.08)$ & 0.32 \\
\hline $\begin{array}{l}\text { Diabetes duration } \\
\text { (per year) }\end{array}$ & $1.02(0.99-1.05)$ & 0.16 & - & - & - & - & - & - \\
\hline $\begin{array}{l}\text { Depression } \\
\text { (HADS-D } \geq 8 p)\end{array}$ & $3.5(1.5-8.0)$ & 0.004 & $3.5(1.5-8.0)$ & 0.004 & $3.4(1.1-10.2)$ & 0.032 & $3.9(1.04-14.8)$ & 0.044 \\
\hline $\begin{array}{l}\mathrm{HbA} 1 \mathrm{c} \\
\text { (per } \mathrm{mmol} / \mathrm{mol})\end{array}$ & $0.99(0.96-1.01)$ & 0.26 & - & - & - & - & - & - \\
\hline $\begin{array}{l}\mathrm{HbA} 1 \mathrm{c}>70 \mathrm{mmol} / \mathrm{mol} \\
(>8.6 \%)\end{array}$ & $0.6(0.2-1.3)$ & 0.17 & - & - & & & & \\
\hline $\mathrm{TC}^{\mathrm{d}}($ per $\mathrm{mmol} / \mathrm{L})$ & $0.9(0.6-1.3)$ & 0.51 & - & - & - & - & - & - \\
\hline $\begin{array}{l}\text { Triglycerides } \\
\text { (per mmol/L) }\end{array}$ & $0.9(0.6-1.5)$ & 0.71 & - & - & - & - & - & - \\
\hline $\mathrm{HDL}^{f}$ (per mmol/L) & $1.3(0.6-3.3)$ & 0.51 & - & - & - & - & - & - \\
\hline $\begin{array}{l}\text { Creatinine } \\
\text { (per } \mu \mathrm{mol} / \mathrm{L})\end{array}$ & $(0.98-1.02)$ & $>0.99$ & - & - & - & - & - & - \\
\hline Abdominal obesity & $0.9(0.3-2.2)$ & 0.77 & - & - & - & - & - & - \\
\hline General obesity & $0.5(0.2-1.8)$ & 0.32 & - & - & - & - & - & - \\
\hline $\begin{array}{l}\text { Systolic BP } \\
\text { (per } \mathrm{mmHg})\end{array}$ & $1.00(0.98-1.03)$ & 0.75 & - & - & - & - & - & - \\
\hline $\begin{array}{l}\text { Diastolic BP } \\
\text { (per } \mathrm{mmHg})\end{array}$ & $1.01(0.97-1.06)$ & 0.54 & - & - & - & - & - & - \\
\hline $\begin{array}{l}\text { Hypoglycaemia } \\
\text { (severe episodes) }\end{array}$ & $2.0(0.5-7.6)$ & 0.32 & - & - & - & - & - & - \\
\hline Smoking & $1.3(0.4-3.5)$ & 0.66 & - & - & - & - & - & - \\
\hline Physical inactivity & $0.8(0.3-2.5)$ & 0.72 & - & - & - & - & - & - \\
\hline $\begin{array}{l}\text { Cardiovascular } \\
\text { complications }\end{array}$ & $4.1(1.1-15.3)$ & 0.034 & $2.4(0.6-9.8)$ & 0.24 & $4.2(0.7-23.2)$ & 0.10 & - & - \\
\hline Antidepressants & $1.2(0.4-3.8)$ & 0.72 & - & - & - & - & - & - \\
\hline$A H D^{i}$ & $1.3(0.6-2.5)$ & 0.50 & - & - & - & - & - & - \\
\hline
\end{tabular}

Number: ${ }^{\mathrm{a}} 283$; ${ }^{\mathrm{b}} 161 ;{ }^{\mathrm{c}} 122$. Hosmer and Lemeshow: ${ }^{\mathrm{a}} 0.891 ;{ }^{\mathrm{b}} 0.218 ;{ }^{\mathrm{c}} 0.634$. Nagelkerke R Square: ${ }^{\mathrm{a}} 0.063 ;{ }^{\mathrm{b}} 0.042 ;{ }^{\mathrm{c}} 0.056 .{ }^{\mathrm{d}}$ Total cholesterol. ${ }^{\mathrm{e}}$ Low-density

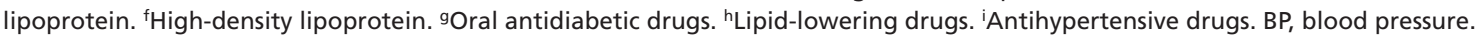

Alzheimer's disease (15). Thus, increased galectin-3 levels might represent a biological link between depression and coronary heart and all-cause mortality, as well as between depression and Alzheimer's disease. However, as this is a cross-sectional study, it cannot be deduced whether depression is primary or secondary to increased galectin-3 levels.

We have previously shown that depression was associated with high $\mathrm{HbA1c}(8)$. In this study, we found no associations between high HbA1c and galectin-3, indicating that they are two independent biomarkers associated with depression. Our results differ from previous research as we did not find any associations between high galectin-3 and age, hypertension, hypercholesterolemia, triglycerides, s-LDL, BMI, s-creatinine or smoking (19, $21,22,23)$. In none of these previous studies had the results been controlled for depression, the results might

$$
\begin{array}{lr}
\text { http://www.endocrineconnections.org } & \text { () } 2018 \text { The authors } \\
\text { https://doi.org/10.1530/EC-18-0108 } & \text { Published by Bioscientifica Ltd }
\end{array}
$$

have been different if they had. However, it must be observed that patients with end-stage renal disease, bipolar disorders, psychotic symptoms or stroke with secondary cognitive deficiency, were excluded which could affect the results in this study. Also, we cannot exclude that some of the metabolic variables, creatinine or cardiovascular complications could have been associated with high galectin-3 if we had chosen another galectin-3 cut-off level. There are several unanswered questions and subjects for future research. The biology of circulating galectin-3 in patients with diabetes and depression is uncertain. Matrix metalloproteinase-9 (MMP-9), which is one of the best described proteases in the CNS, targets galectin-3 for cleavage (34). Galectin-3 is, however, also a positive downstream regulator of MMP-9 expression (35). Increased levels of MMP-9 have been described during depressive episodes in patients

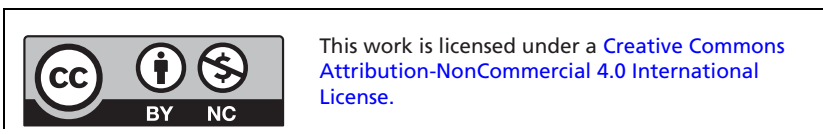


with bipolar depression (36), in patients with unipolar major depressive disorder (37), as well as in the brains of persons with Alzheimer's disease (38). MMP-9 has also been suggested to play a main role in synaptic trafficking and modification of glutamate receptors, such as the N-methyl-D-aspartate receptor (39), which is of particular interest when it comes to depression and treatment of this condition (40). Future studies should thus focus on MMP-9 in addition to galectin-3 in patients with diabetes and depression, which might give valuable information about the pathogenesis.

Whether galactin-3 could be a good diagnostic marker for depression in T1D needs to be further investigated. Additional larger studies comparing galectin-3 levels in depressed and non-depressed persons, both in persons with and without T1D will be necessary, as well as longitudinal studies. Can galectin-3 be used for the evaluation of the efficacy of the treatment for depression? It would be of interest to measure galectin- 3 at the initiation of antidepressant medication or psychotherapy and follow the galectin-3 values during therapy. It would also be of interest to explore whether depressed T1D patients with high galectin-3 level have increased risk for Alzheimer's disease, renal dysfunction, cardiac failure and mortality. Which galectin-3 levels are damaging for the heart, for the brain or for the kidneys? For how long can a person have increased galectin-3 levels without risking damage to the heart or risking the development of Alzheimer's disease? Can galectin-3 be a target for treatment? In further research, we suggest that when associations between galectin-3 and somatic parameters are explored, the results should be adjusted for depression.

In conclusion, depression was the only examined variable associated with high circulating galectin-3 $(\geq 2.562 \mu \mathrm{g} / \mathrm{l})$ in the 283 patients with T1D. The association between depression and galectin-3 has not to our knowledge been explored previously, neither in persons with T1D nor in those without T1D. Higher galectin-3 levels might contribute to the increased risk for Alzheimer's disease, cardiovascular and all-cause mortality observed in patients with depression. Potentially, in the future, high galectin-3 levels could be used as indicators for depression, and treatment targeting galactin-3 might be developed to improve the prognosis for patients with high galectin-3 levels.

\section{Declaration of interest}

The authors declare that there is no conflict of interest that could be perceived as prejudicing the impartiality of the research reported.

\section{Funding}

This research was supported by the Research and Development Fund of Health Care, Region Kronoberg, Växjö, Sweden; by the Research Council of South Eastern Sweden (FORSS), Linköping, Sweden; and by the Patient Diabetes Organisation of Southern Sweden (Sydsvenska Diabetesföreningen) Malmö, Sweden. The funding sources were not involved in the collection, analysis or interpretation of data, in the writing of the report, or in the decision to submit the article for publication.

\section{Authors' contribution statement}

E O M, J D, M T and M H participated as investigators and reviewed, edited and approved the final version of the manuscript. E O M initiated the study of depression in diabetes, performed the statistical analysis, is the guarantor of this work and, as such, had full access to all the data in the study and takes responsibility for the integrity of the data and the accuracy of the data analysis. M H suggested that galectin-3 would be of interest to study. $\mathrm{E} \mathrm{O} \mathrm{M}$ and $\mathrm{M} \mathrm{H}$ wrote the manuscript. J D performed and validated the galectin- 3 analyses. E O M and M T organized the recruitment of patients and collection of data.

\section{Acknowledgements}

The authors are grateful to Anna Lindgren, at the Department of Mathematical Statistics, Lund University, Lund, Sweden, for her statistical skills.

\section{References}

1 Egede LE, Nietert PJ \& Zheng D. Depression and all-cause and coronary heart disease mortality among adults with and without diabetes. Diabetes Care 200528 1339-1345. (https://doi.org/10.2337/ diacare.28.6.1339)

2 Penninx BW, Milaneschi Y, Lamers F \& Vogelzangs N. Understanding the somatic consequences of depression: biological mechanisms and the role of depression symptom profile. BMC Medicine 201311129. (https://doi.org/10.1186/1741-7015-11-129)

3 Korczak DJ, Pereira S, Koulajian K, Matejcek A \& Giacca A. Type 1 diabetes mellitus and major depressive disorder: evidence for a biological link. Diabetologia 201154 2483-2493. (https://doi. org/10.1007/s00125-011-2240-3)

4 Wang B, An X, Shi X \& Zhang J. MANAGEMENT OF ENDOCRINE DISEASE: Suicide risk in patients with diabetes: a systematic review and meta-analysis. European Journal of Endocrinology $2017 \mathbf{1 7 7}$ R169-R181. (https://doi.org/10.1530/EJE-16-0952)

5 Tynan RJ, Weidenhofer J, Hinwood M, Cairns MJ, Day TA \& Walker FR. A comparative examination of the anti-inflammatory effects of SSRI and SNRI antidepressants on LPS stimulated microglia. Brain, Behavior, and Immunity 201226 469-479. (https://doi. org/10.1016/j.bbi.2011.12.011)

6 Ma Y, Balasubramanian R, Pagoto SL, Schneider KL, Hébert JR, Phillips LS, Goveas JS, Culver AL, Olendzki BC \& Beck J. Relations of depressive symptoms and antidepressant use to body mass index and selected biomarkers for diabetes and cardiovascular disease. American Journal of Public Health 2013103 e34-e43. (https://doi.org/10.2105/ AJPH.2013.301394)

7 Raison CL, Capuron L \& Miller AH. Cytokines sing the blues: inflammation and the pathogenesis of depression. Trends in Immunology 200627 24-31. (https://doi.org/10.1016/j. it.2005.11.006)

8 Melin EO, Thunander M, Svensson R, Landin-Olsson M \& Thulesius HO. Depression, obesity and smoking were independently associated with inadequate glycemic control in patients with type 
1 diabetes. European Journal of Endocrinology 2013168 861-869. (https://doi.org/10.1530/eje-13-0137)

9 Melin EO, Thunander M, Landin-Olsson M, Hillman M \& Thulesius HO. Depression, smoking, physical inactivity and season independently associated with midnight salivary cortisol in type 1 diabetes. BMC Endocrine Disorders 201414 75. (https://doi. org/10.1186/1472-6823-14-75)

10 Melin EO, Thunander M, Landin-Olsson M, Hillman M \& Thulesius HO. Depression differed by midnight cortisol secretion, alexithymia and anxiety between diabetes types: a cross sectional comparison. BMC Psychiatry 201717 335. (https://doi.org/10.1186/ s12888-017-1495-8)

11 Melin EO, Svensson R, Thunander M, Hillman M, Thulesius HO \& Landin-Olsson M. Gender, alexithymia and physical inactivity associated with abdominal obesity in type 1 diabetes mellitus: a cross sectional study at a secondary care hospital diabetes clinic. $B M C$ Obesity 20174 21. (https://doi.org/10.1186/s40608-017-0157-1)

12 Gruson D \& Ko G. Galectins testing: new promises for the diagnosis and risk stratification of chronic diseases? Clinical Biochemistry 2012 45 719-726. (https://doi.org/10.1016/j.clinbiochem.2012.04.009)

13 Nio-Kobayashi J. Tissue-and cell-specific localization of galectins, $\beta$-galactose-binding animal lectins, and their potential functions in health and disease. Anatomical Science International 201792 25-36. (https://doi.org/10.1007/s12565-016-0366-6)

14 Sharma UC, Pokharel S, van Brakel TJ, van Berlo JH, Cleutjens JP, Schroen B, André S, Crijns HJ, Gabius HJ \& Maessen J. Galectin-3 marks activated macrophages in failure-prone hypertrophied hearts and contributes to cardiac dysfunction. Circulation 2004110 3121-3128. (https://doi.org/10.1161/01.CIR.0000147181.65298.4D)

15 Wang X, Zhang S, Lin F, Chu W \& Yue S. Elevated galectin-3 levels in the serum of patients with Alzheimer's disease. American Journal of Alzheimer's Disease and Other Dementias 201530 729-732. (https:// doi.org/10.1177/1533317513495107)

16 Shin T. The pleiotropic effects of galectin-3 in neuroinflammation: a review. Acta Histochemica 2013115 407-411. (https://doi. org/10.1016/j.acthis.2012.11.010)

17 Burguillos MA, Svensson M, Schulte T, Boza-Serrano A, GarciaQuintanilla A, Kavanagh E, Santiago M, Viceconte N, OlivaMartin MJ \& Osman AM. Microglia-secreted galectin-3 acts as a toll-like receptor 4 ligand and contributes to microglial activation. Cell Reports 201510 1626-1638. (https://doi.org/10.1016/j. celrep.2015.02.012)

18 Yip PK, Carrillo-Jimenez A, King P, Vilalta A, Nomura K, Chau CC, Egerton AMS, Liu ZH, Shetty AJ, Tremoleda JL, et al. Galectin-3 released in response to traumatic brain injury acts as an alarmin orchestrating brain immune response and promoting neurodegeneration. Scientific Reports 20177 41689. (https://doi. org/10.1038/srep41689)

19 Ho JE, Liu C, Lyass A, Courchesne P, Pencina MJ, Vasan RS, Larson MG \& Levy D. Galectin-3, a marker of cardiac fibrosis, predicts incident heart failure in the community. Journal of the American College of Cardiology 201260 1249-1256. (https://doi. org/10.1016/j.jacc.2012.04.053)

20 Imran TF, Shin HJ, Mathenge N, Wang F, Kim B, Joseph J, Gaziano JM $\&$ Djoussé L. Meta-analysis of the usefulness of plasma galectin-3 to predict the risk of mortality in patients with heart failure and in the general population. American Journal of Cardiology 2017119 57-64. (https://doi.org/10.1016/j.amjcard.2016.09.019)

21 Hrynchyshyn N, Jourdain P, Desnos M, Diebold B \& Funck F. Galectin-3: a new biomarker for the diagnosis, analysis and prognosis of acute and chronic heart failure. Archives of Cardiovascular Diseases 2013106 541-546. (https://doi.org/10.1016/j.acvd.2013.06.054)

22 Weigert J, Neumeier M, Wanninger J, Bauer S, Farkas S, Scherer MN, Schnitzbauer A, Schäffler A, Aslanidis C \& Schölmerich J. Serum galectin-3 is elevated in obesity and negatively correlates with glycosylated hemoglobin in type 2 diabetes. Journal of Clinical
Endocrinology and Metabolism 201095 1404-1411. (https://doi. org/10.1210/ic.2009-1619)

23 van der Velde AR, Meijers WC, van den Heuvel ER, Bakker SJ, van Gilst WH, van der Harst P, Hillege H \& de Boer RA. Determinants of temporal changes in galectin-3 level in the general population: data of PREVEND. International Journal of Cardiology 2016222 385-390. (https://doi.org/10.1016/j.ijcard.2016.07.241)

24 Pricci F, Leto G, Amadio L, Iacobini C, Romeo G, Cordone S, Gradini R, Barsotti P, Liu FT \& Di Mario U. Role of galectin-3 as a receptor for advanced glycosylation end products. Kidney International $2000 \mathbf{5 8}$ S31-S39. (https://doi.org/10.1046/j.15231755.2000.07706.x)

25 Melin EO, Svensson R, Gustavsson SÅ, Winberg A, DenwardOlah E, Landin-Olsson M \& Thulesius HO. Affect school and script analysis versus basic body awareness therapy in the treatment of psychological symptoms in patients with diabetes and high HbA1c concentrations: two study protocols for two randomized controlled trials. Trials 201617 221. (https://doi.org/10.1186/s13063-0161347-8)

26 Melin E. Psychosomatic aspects on diabetes and chronic pain Alexithymia, depression and salivary cortisol. The Affect School and Script Analysis Therapy. PhD Thesis. Lund, Sweden: Lund University, 2014

27 Lind M, Svensson AM, Kosiborod M, Gudbjörnsdottir S, Pivodic A, Wedel H, Dahlqvist S, Clements M \& Rosengren A. Glycemic control and excess mortality in type 1 diabetes. New England Journal of Medicine 2014371 1972-1982. (https://doi.org/10.1056/ NEJMoa1408214)

28 Eeg-Olofsson K, Cederholm J, Nilsson PM, Gudbjörnsdóttir S \& Eliasson B. Glycemic and risk factor control in type 1 diabetes. Diabetes Care 200730 496-502. (https://doi.org/10.2337/dc06-1406)

29 Zigmond AS \& Snaith RP. The hospital anxiety and depression scale. Acta Psychiatrica Scandinavica 198367 361-370. (https://doi. org/10.1111/j.1600-0447.1983.tb09716.x)

30 Bocéréan C \& Dupret E. A validation study of the Hospital Anxiety and Depression Scale (HADS) in a large sample of French employees. BMC Psychiatry 201414 1-11. (https://doi.org/10.1186/s12888-0140354-0)

31 Ridker PM. LDL cholesterol: controversies and future therapeutic directions. Lancet 2014384 607-617. (https://doi.org/10.1016/S01406736(14)61009-6)

32 Tanamas SK, Permatahati V, Ng WL, Backholer K, Wolfe R, Shaw JE \& Peeters A. Estimating the proportion of metabolic health outcomes attributable to obesity: a cross-sectional exploration of body mass index and waist circumference combinations. BMC Obesity 201634. (https://doi.org/10.1186/s40608-016-0085-5)

33 The National Board of Health and Welfare. Swedish National Guidelines for Diabetes, 2009. (available at: https://www. socialstyrelsen.se/english)

34 Ochieng J, Fridman R, Nangia-Makker P, Kleiner DE, Liotta LA, Stetler-Stevenson WG \& Raz A. Galectin-3 is a novel substrate for human matrix metalloproteinases-2 and-9. Biochemistry 199433 14109-14114. (https://doi.org/10.1021/bi00251a020)

35 Dange MC, Agarwal AK \& Kalraiya RD. Extracellular galectin-3 induces MMP9 expression by activating p38 MAPK pathway via lysosome-associated membrane protein-1 (LAMP1). Molecular and Cellular Biochemistry 2015404 79-86. (https://doi.org/10.1007/ s11010-015-2367-5)

36 Rybakowski JK, Remlinger-Molenda A, Czech-Kucharska A, Wojcicka M, Michalak M \& Losy J. Increased serum matrix metalloproteinase-9 (MMP-9) levels in young patients during bipolar depression. Journal of Affective Disorders 2013146 286-289. (https:// doi.org/10.1016/j.jad.2012.07.019)

37 Domenici E, Willé DR, Tozzi F, Prokopenko I, Miller S, McKeown A, Brittain C, Rujescu D, Giegling I \& Turck CW. Plasma protein biomarkers for depression and schizophrenia by multi analyte
This work is licensed under a Creative Commons Attribution-NonCommercial 4.0 International License. 
profiling of case-control collections. PLoS ONE 20105 e9166. (https://doi.org/10.1371/journal.pone.0009166)

38 Mizoguchi H, Yamada K \& Nabeshima T. Matrix metalloproteinases contribute to neuronal dysfunction in animal models of drug dependence, Alzheimer's disease, and epilepsy. Biochemistry Research International 20112011 681385. (https://doi. org/10.1155/2011/681385)

39 Michaluk P, Mikasova L, Groc L, Frischknecht R, Choquet D \& Kaczmarek L. Matrix metalloproteinase-9 controls NMDA receptor surface diffusion through integrin $\beta 1$ signaling. Journal of Neuroscience 200929 6007-6012. (https://doi.org/10.1523/ JNEUROSCI.5346-08.2009)

40 Niciu MJ, Henter ID, Luckenbaugh DA, Zarate CA Jr \& Charney DS. Glutamate receptor antagonists as fast-acting therapeutic alternatives for the treatment of depression: ketamine and other compounds. Annual Review of Pharmacology and Toxicology 201454 119-139. (https://doi.org/10.1146/annurevpharmtox-011613-135950)

Received in final form 2 May 2018

Accepted 14 May 2018

Accepted Preprint published online 14 May 2018 http://www.endocrineconnections.org https://doi.org/10.1530/EC-18-0108 (c) 2018 The authors Published by Bioscientifica Ltd

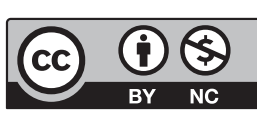

This work is licensed under a Creative Commons Attribution-NonCommercial 4.0 International License. 